\title{
Host-Derived Biomarkers for Risk Assessment of Invasive Fungal Diseases
}

\author{
Cristina Cunha, Samuel M. Gonçalves, and Agostinho Carvalho
}

\begin{abstract}
Invasive fungal diseases are major complications associated with the treatment of hematologic malignancies. The integration of host-derived biomarkers into clinical processes to predict the risk and progression of fungal disease is a promising approach in immunocompromised patients. Recent insights into human antifungal immunity have highlighted the remarkable influence of host genetics in modulating susceptibility to infection. In this chapter, we describe protocols to examine human genetic variation and to assess its functional consequences using the pattern recognition receptor PTX3 as an example.
\end{abstract}

Key words Invasive fungal disease, Single nucleotide polymorphism (SNP), Host biomarkers, Long pentraxin 3 (PTX3), Antifungal immunity, Immunocompromised patients, Risk stratification, Personalized medicine

\section{Introduction}

Invasive fungal diseases, particularly invasive aspergillosis (IA), are major complications associated with the treatment of hematologic malignancies [1]. Vaccines are not available, and despite noteworthy recent developments in diagnostic and therapeutic approaches, these diseases remain associated with unacceptable mortality rates $[2,3]$. Concerns over excessive prescription of antifungal drugs and the remarkable burden these diseases convey to the healthcare systems are inspiring a shift from universal prophylaxis to risk stratification and preemptive approaches. Recent evidence continues to highlight the complexity of the multiple fungal-sensing immune systems and the remarkable influence of the host genetics in the ability to control infection risk and its progression. As a result of our improved understanding of the host-fungus interaction, several relevant target genes (and associated genetic variants) with the potential to be exploited in future personalized medical interventions in high-risk settings based on individual genetic risk have been identified. 
Chronic granulomatous disease and autosomal-dominant hyper-IgE syndrome (AD-HIES) are the most common examples of primary immunodeficiencies typically associated with susceptibility to IA [4]. These severe immune deficiencies with monogenic inheritance are usually limited to a very small number of individuals or families, but the identification of genetic defects is very informative on immune defense mechanisms. For most individuals however, genetic propensity to fungal disease has a polygenic inheritance, acting in concert with other clinical predisposing variants such as chemotherapy-induced neutropenia. Our increasing ability to analyze human variability at the DNA level has made possible the identification of several host genetic variants amenable to use in the categorization of patients with a high risk of infection and to target antifungal therapy (reviewed in $[5,6]$ ). However, the clinical translation of this active field of research is still limited, mostly due to the heterogeneity of cohorts, sample size, case and control selection bias, and statistical misconceptions.

Among the most encouraging examples reported to date, a donor haplotype in Toll-like receptor 4 (TLR4) underlying a delayed $\mathrm{T}$ cell and natural killer $\mathrm{T}$ cell immune reconstitution [7] has been disclosed as an important risk factor for developing IA in recipients of allogeneic hematopoietic stem cell transplantation (HSCT) [8]. In addition, TLR4 variants have been previously linked with chronic aspergillosis in immunocompetent individuals [9] and fungal colonization in HSCT recipients [10]. However, and since the fungal ligand (or the host-derived molecule released in response to fungal infection) for TLR4 remains debated, uncovering the exact mechanism(s) through which TLR4 deficiency impacts antifungal immunity is required to strengthen the prognostic significance of its genetic variation.

It is noteworthy that, in addition to TLR4, genetic variation in other TLRs has also been proposed to influence the risk of IA. For example, a regulatory variant decreasing the expression of TLR3 in dendritic cells was found to impair the recognition of fungal nucleic acids and to compromise the efficient priming of protective memory CD8+ $\mathrm{T}$ cell responses, thereby rendering HSCT recipients more prone to develop IA [11]. Ultimately, the evaluation of regulatory variation impacting adaptive immunity might help to enhance the discriminatory potential of recent immunodiagnostic strategies based on the evaluation of fungal-specific adaptive immune responses [12]. Of interest, damage perception is coupled with pathogen-sensing pathways (especially intracellular TLRs) to restrain inflammation in experimental aspergillosis [13]. Therefore, it is not surprising that genetic variants determining a hyperactivation in danger signaling axes, and presumably underlying exuberant inflammatory responses, were also found to increase the risk for IA [14]. Finally, other examples include genetic variants in TLR I and TLR6 [15], and TLR5 [16], but further studies are warranted to definitely assure their predictive potential for fungal disease. 
Dectin-1 deficiency has consistently been reported to contribute to susceptibility to IA [17-19]. In particular, a stop codon polymorphism in Dectin-1 (CLEC7A) compromising the surface expression of the receptor in myeloid cells and downstream cytokine production in response to fungal infection [20] significantly increased the risk of IA in HSCT recipients [18]. The fact that Dectin-1 deficiency in both transplant counterparts synergized towards risk of IA highlighted for the first time the pivotal contribution of non-hematopoietic Dectin-1 in antifungal immunity. The prominent biological plausibility of this association suggests Dectin- 1 as an attractive candidate not only in risk stratification measures but also in immunotherapeutic strategies aiming at countering the defective Dectin-1 function.

Numerous positive associations between genetic variants in cytokine and chemokine genes and risk of IA have also been reported [21-26]. Most of these initial reports were however largely underpowered and performed in poorly characterized cohorts, thereby precluding definite conclusions about genetic variants affecting cytokine production in the context of IA. There are however some exceptions that assume particular relevance given the robust study design and functional validation $[22,27]$. Among the exceptions, a haplotype in $\mathrm{C}-\mathrm{X}-\mathrm{C}$ motif ligand 10 (CXCL10) was mechanistically correlated to a deficient expression of this chemokine in dendritic cells and, accordingly, high levels of CXCLl 0 were also more frequently observed among patients surviving IA compared to unaffected controls [22]. More recently, variants in the genes encoding for IL-1 $\beta$ and beta-defensin 1 (DEFBl) were reported to increase the risk of IA in solid organ transplant recipients, supposedly by impairing fungal-induced proinflammatory cytokine secretion by mononuclear cells [27].

Next-generation sequencing technologies now provide exciting possibilities to pin down essential steps in the host-fungus interaction at a level of complexity previously unanticipated. The first genome-wide association studies (GWAS) exploring host susceptibility to IA are underway and are expected to provide unbiased insights into the genetic defects contributing to development of IA. The plausibility of these approaches has been recently demonstrated in invasive fungal diseases, in which functional genomics analyses have allowed the identification of new important players controlling susceptibility to candidemia [28, 29]. Finally, genetic analysis of gene expression represents another powerful approach enabling insights into the human genomic landscape by generating expression maps that might be revealed extremely useful for the functional interpretation of noncoding variants likely to arise from ongoing genome-wide initiatives [30].

A number of alternative strategies using mouse models of infection as a starting point have also been employed to define candidate genes involved in susceptibility to IA [31, 32]. Genetic mapping analysis of survival data of animals subjected to experi- 
mental infection led to the identification of a non-synonymous polymorphism in human plasminogen $(P L G)$, a regulatory molecule with opsonic properties, as an important modulator of susceptibility to IA in humans [32]. Genetic deficiency of additional molecules with opsonic activity-e.g., mannose-binding lectin (MBL) [33] and the long pentraxin 3 (PTX3) [34] - has also been disclosed as a major determinant of susceptibility to IA, pointing to a key contribution of the innate humoral arm to an adequate activation of protective antifungal immune responses. This is corroborated by the validation of the association of a PTX3 haplotype and increased risk of IA in two independent, high-powered genetic association studies $[34,35]$. The involved haplotype was found to compromise the alveolar availability of PTX3 and, at a cellular level, its expression during the developmental programming of neutrophil precursors in the bone marrow, leading to defective antifungal effector mechanisms of newly reconstituted neutrophils [34]. Importantly, this association was also recently replicated in recipients of lung transplant [36], highlighting a potential applicability of these markers in predicting infection across patients with intrinsically different predisposing conditions. Of interest, the alveolar levels of PTX3 have been demonstrated to discriminate microbiologically confirmed pneumonia in mechanically ventilated patients [37]. Given that these levels vary individually according to host genotypes [34], we can envisage the quantification of PTX3 in bronchoalveolar lavage fluids as a complementary surveillance measure in addition to the currently available diagnostic approaches. Finally, the fact that exogenous administration of PTX3 is able to revert the genetic defect in vitro [34] further highlights the potential of PTX3-based immunotherapies to treat (or prevent) IA [38].

Although the overall weight of the antifungal immune response is certainly driven by adding effects of single genetic factors and their complex interactions with clinical immune dysfunctions, PTX3 represents the most robust genetic marker identified to date. These consistent findings are expected to lay the foundations for well-designed prospective trials ultimately endorsing PTX3-based genetic testing in risk stratification approaches for IA. In this chapter, we will use PTX3 as an example to describe protocols to assess genetic variation in PTX3 associated with susceptibility to IA, and to evaluate the associated functional consequences in circulating neutrophils from patients at-risk.

\section{Materials}

Prepare all solutions using ultrapure water and cell-culture grade reagents. Prepare and store all reagents at room temperature (unless indicated otherwise). Carefully follow all waste disposal regulations when disposing of human waste materials. 


\subsection{DNA Isolation \\ 2.2 Single Nucleotide Polymorphism (SNP) Genotyping}

\subsection{Neutrophil Isolation}

\subsection{Neutrophil Lysis}

\subsection{ELISA for PTX3}

2.6 Assessment of Neutrophil Effector Functions
1. Quick-gDNA ${ }^{\mathrm{TM}}$ MiniPrep Kit (Zymo Research).

1. KASP ${ }^{\text {тм }}$ Assay Mix for the rs2305619, rs3816527, and rs1840680 SNPs in PTX3 and KASP ${ }^{\mathrm{TM}}$ Master Mix (LGC Genomics).

1. Histopaque 1077 (Sigma-Aldrich).

2. $\mathrm{NaCl} 0.2,0.9$, and $1.6 \%$.

3. Dextran T-500 from Alfa Aesar (cat \#: J63702) 3\% in 0.9\% $\mathrm{NaCl}$ (dextran/saline solution).

4. PBS: $\mathrm{NaCl} 137 \mathrm{mM}, \mathrm{KCl} 2.7 \mathrm{mM}, \mathrm{Na}_{2} \mathrm{HPO}_{4} 8.1 \mathrm{mM}$, $\mathrm{KH}_{2} \mathrm{PO}_{4} 1.5 \mathrm{mM}, \mathrm{pH} 7.2-7.4,0.2 \mu \mathrm{m}$ filtered.

1. Neutrophil lysis buffer: Tris-HCl 10 mM, EDTA 5 mM, NP40 $1 \%$, and $1 \times$ protease inhibitors.

1. ELISA to detect human PTX3, for example the Pentraxin 3/ TSG-14 DuoSet ELISA (R\&D systems).

2. PBS (prepared as above).

3. Wash buffer: Tween $200.05 \%$ in PBS, pH 7.2-7.4.

4. Reagent diluent: bovine serum albumin (BSA) $1 \%$ in PBS, $\mathrm{pH}$ 7.2-7.4 (stored at $4^{\circ} \mathrm{C}$ ).

5. Substrate solution: 1:1 mixture of color reagent $\mathrm{A}\left(\mathrm{H}_{2} \mathrm{O}_{2}\right)$ and color reagent $\mathrm{B}$ (tetramethylbenzidine).

6. Stop solution: $\mathrm{H}_{2} \mathrm{SO}_{4} 2 \mathrm{~N}$.

1. Live conidia from Aspergillus fumigatus.

2. Fluorescein isothiocyanate (FITC) (Sigma-Aldrich).

3. RPMI Medium 1640 (Thermo Fisher Scientific).

4. Sabouraud Dextrose agar $\left(\right.$ BD Difco $\left.{ }^{\mathrm{TM}}\right)$.

\section{Methods}

\subsection{Isolation of Genomic DNA} from Peripheral Blood
For the purpose of this chapter, genetic variants in PTX3 are given as examples of common variants that have been described to influence the risk of IA; however, these can be replaced with other known and novel genetic markers. The methods addressing the functional consequences of these variants and described below have been verified in human circulating neutrophils.

Reagents used to isolate genomic DNA are part of the QuickgDNA $^{\mathrm{TM}}$ MiniPrep Kit. By using the innovative Zymo-Spin ${ }^{\mathrm{TM}}$ Column technology, this kit yields highly purified RNA-free DNA, bypassing the need for RNase A treatment and excluding the use 
of proteinase $\mathrm{K}$ and organic denaturants, thereby ensuring high quality for sensitive downstream applications, including SNP analysis. In addition, all reagents are compatible with commonly used anticoagulants (i.e., EDTA, heparin, citrate) in blood drawing procedures. Additional equipment required includes a microcentrifuge and a vortex.

1. Add $400 \mu \mathrm{L}$ of lysis buffer to $100 \mu \mathrm{L}$ of whole blood (4:1). Mix thoroughly by vortexing and allow the mixture to rest for 5-10 $\mathrm{min}$ at room temperature (see Note 1 ).

2. Transfer the mixture to a Zymo-Spin ${ }^{\mathrm{TM}}$ column in a collection tube and centrifuge at $10,000 \times g$ for $1 \mathrm{~min}$.

3. Wash the column with $200 \mu \mathrm{L}$ of DNA pre-wash buffer and centrifuge as before.

4. Add $500 \mu \mathrm{L}$ of DNA wash buffer to the column and centrifuge as before.

5. Elute the DNA in $50 \mu \mathrm{L}$ of elution buffer and collect the purified DNA in a clean microcentrifuge tube (see Note 2).

6. Determine the concentration of DNA in each sample by light spectrophotometry (e.g., NanoDrop) using the elution buffer as blank.

\subsection{Genotyping of PTX3 SNPS}

The Kompetitive Allele-Specific PCR (KASPar) chemistry (LGC Genomics) is hereafter used as an example of a commercial ondemand assay to perform genotyping. This kit contains a KASP ${ }^{\mathrm{TM}}$ Assay Mix that is specific to the SNPs under analysis and consists of two competitive, allele-specific forward primers and one common reverse primer. Each forward primer incorporates an additional tail sequence that corresponds with one of two universal fluorescent resonance energy transfer (FRET) cassettes (FAM and HEX) present in the KASP ${ }^{\mathrm{TM}}$ Master Mix. This mix also includes the $\mathrm{ROX}^{\mathrm{TM}}$ passive reference dye, Taq polymerase, free nucleotides, and $\mathrm{MgCl}_{2}$ in an optimized buffer solution.

1. Vortex thoroughly all the components of the KASPar assay prior to use.

2. Dispense $5 \mu \mathrm{L}$ of each DNA sample onto a qPCR-compatible 96-well plate ( see Note 3). Make sure to include at least three non-template controls (NTC) containing ultrapure water.

3 . Prepare a master mix containing $5 \mu \mathrm{L}$ of $2 \times$ reaction mix and $0.14 \mu \mathrm{L}$ of the primer mix for each sample to be analyzed.

4. Add $5 \mu \mathrm{L}$ of the master mix to each DNA and NTC well.

5. Seal the 96-well plate carefully and run the qPCR in a compatible instrument according to the following thermal profile (see Notes 4 and $\mathbf{5}$ ). 


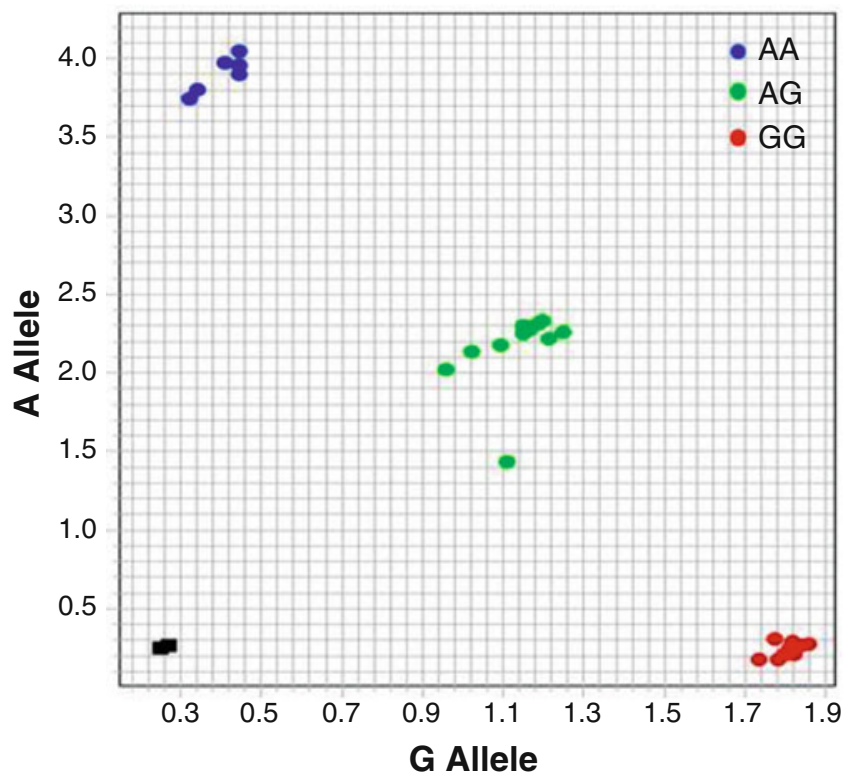

Fig. 1 Typical allelic discrimination plot obtained for the rs2305619 SNP in the PTX3 gene. Genotyping was performed using KASPar chemistry in a 7500 Fast qPCR system (Applied Biosystems)

\begin{tabular}{|c|c|c|c|c|c|}
\hline \multirow{2}{*}{$\begin{array}{l}\text { Holding stage } \\
94^{\circ} \mathrm{C}\end{array}$} & \multicolumn{2}{|c|}{ Cycling stage (10 cycles) } & \multicolumn{2}{|c|}{ Cycling stage (32 cycles) } & \multirow{2}{*}{$\begin{array}{l}\begin{array}{l}\text { Post-PCR read } \\
\text { (holding stage) }\end{array} \\
25^{\circ} \mathrm{C}\end{array}$} \\
\hline & $94^{\circ} \mathrm{C}$ & $61^{\circ} \mathrm{C}$ & $96{ }^{\circ} \mathrm{C}$ & $55^{\circ} \mathrm{C}$ & \\
\hline $15 \mathrm{~min}$ & $20 \mathrm{~s}$ & $\begin{array}{l}60 \mathrm{~s} \\
\left(-0.6^{\circ} \mathrm{C} / \text { cycle }\right)\end{array}$ & $20 \mathrm{~s}$ & $60 \mathrm{~s}$ & $60 \mathrm{~s}$ \\
\hline
\end{tabular}

6. Perform the allelic discrimination by reading fluorescence at $25{ }^{\circ} \mathrm{C}$ (Fig. 1).

7. In the event clear genotyping clusters are not observed, the plate should be thermally cycled further (three additional cycles of $20 \mathrm{~s}$ at $94^{\circ} \mathrm{C}$ and $60 \mathrm{~s}$ at $57^{\circ} \mathrm{C}$ ) and read again at $25{ }^{\circ} \mathrm{C}$.

3.3 Isolation of Circulating Neutrophils
1. Dilute the collected whole blood at a $1: 4$ proportion with $0.9 \% \mathrm{NaCl}$.

2. Layer $10 \mathrm{~mL}$ of Histopaque 1077 beneath the diluted whole blood using a pipette or a syringe (see Note 6).

3. Centrifuge at $400 \times g$ for $40 \mathrm{~min}$ at $20{ }^{\circ} \mathrm{C}$ without brake ( see Note 7).

4. Aspirate and discard the supernatant and resuspend the granulocyte/red blood cell (RBC) pellet in $20 \mathrm{~mL}$ of PBS.

5. Add an equal volume of dextran/saline solution, mix and incubate in the upright position for approximately $30 \mathrm{~min}$ at room temperature. 


\subsection{Preparation of Neutrophil Lysates}

\subsection{Measurement of Intracellular PTX3 in Neutrophils by ELISA}

6. Aspirate and save the leukocyte-rich plasma (upper layer) using a pipette.

7. Pellet cells from the plasma by centrifuging at $250 \times g$ for $10 \mathrm{~min}$ at $4{ }^{\circ} \mathrm{C}($ see Note 8$)$.

8. To remove residual $\mathrm{RBC}$, subject cells to hypotonic lysis by resuspending the pellet in $20 \mathrm{~mL}$ of cold $0.2 \% \mathrm{NaCl}$ for exactly $30 \mathrm{~s}$.

9. Restore isotonicity by adding $20 \mathrm{~mL}$ of ice-cold $1.6 \% \mathrm{NaCl}$.

10. Centrifuge at $250 \times g$ for $6 \mathrm{~min}$ at $4{ }^{\circ} \mathrm{C}$ and discard the supernatant. Repeat steps 8 and 9 until the cell pellet appears free of RBC.

11. Resuspend cells in ice-cold PBS and determine cell concentration by counting in a Neubauer chamber.

1. Transfer $10^{6}$ neutrophils into an Eppendorf tube and remove the supernatant by centrifuging at $250 \times g$ for $6 \mathrm{~min}$ at $4{ }^{\circ} \mathrm{C}$.

2. Add $200 \mu \mathrm{L}$ of lysis buffer and incubate $5 \mathrm{~min}$ on ice.

3 . Collect the cell lysate by centrifugation at $12,000 \times g$ for $15 \mathrm{~min}$ at $4{ }^{\circ} \mathrm{C}$.

4. Store at $-80{ }^{\circ} \mathrm{C}$ until the determination of intracellular PTX3 by ELISA.

All reagents from the ELISA kit for PTX3 should be brought to room temperature before use and the reconstituted components should be allowed to sit for at least $15 \mathrm{~min}$ with gentle agitation. Working dilutions should be prepared according to the manufacturer's instructions and used immediately.

1. Dilute the capture antibody to the working concentration using PBS and coat a 96-well microplate with $100 \mu \mathrm{L}$ per well.

2. Seal the plate and incubate overnight at room temperature.

3. Wash each well three times with $400 \mu \mathrm{L}$ of wash buffer (see Note 9).

4. Block the plate by adding $300 \mu \mathrm{L}$ of reagent diluent to each well and incubate for $1 \mathrm{~h}$ at room temperature. Repeat the washing step as above.

5. Add $100 \mu \mathrm{L}$ of sample (it may be necessary to dilute the samples prior use) or standards in reagent diluent per well. Cover the plate with an adhesive strip and incubate overnight at $4{ }^{\circ} \mathrm{C}$.

6. Repeat the washing step as above.

7. Add $100 \mu \mathrm{L}$ of the diluted detection antibody to each well and incubate for $2 \mathrm{~h}$ at room temperature.

8. Repeat the washing step as above. 
9. Add $100 \mu \mathrm{L}$ of the working dilution of streptavidin-horseradish peroxidase (HRP) to each well.

10. Seal the plate and incubate at room temperature for $20 \mathrm{~min}$ (see Note 10).

11. Repeat the washing step as above.

12. Add $100 \mu \mathrm{L}$ of substrate solution to each well and incubate at room temperature for $20 \mathrm{~min}$ (see Note 11).

13. Add $50 \mu \mathrm{L}$ of stop solution to each well and gently tap the plate to ensure thorough mixing.

14. Determine the optical density of each well immediately using a microplate reader set to $450 \mathrm{~nm}$ (see Note 12).

3.6 Measurement of Phagocytosis in Neutrophils
3.7 Evaluation

of Neutrophil Fungicidal Activity
1. To estimate phagocytic activity, plate $5 \times 10^{5}$ freshly isolated neutrophils in $12 \mathrm{~mm}$ glass coverslips coated with serum proteins or purified fibrinogen in a 24 -well plate.

2. Add live FITC-labeled conidia of $A$. fumigatus at an effector to fungal cell ratio of $1: 5$ in a final volume of $500 \mu \mathrm{L}$ (see Note 13).

3. Incubate at $37{ }^{\circ} \mathrm{C}$ for $\mathrm{l} \mathrm{h}$ in a humidified $\mathrm{CO}_{2}$ culture chamber.

4. After incubation, remove the non-adherent conidia by washing carefully twice with PBS.

5. Add $300 \mu \mathrm{L}$ of trypan blue ( $1 \mathrm{mg} / \mathrm{mL}$ in PBS) to each well for $15 \mathrm{~min}$ at $25{ }^{\circ} \mathrm{C}$ to quench the fluorescence of bound but uningested conidia.

6. Wash twice with PBS and fix the cells in $1 \%$ paraformaldehyde for $15 \mathrm{~min}$.

7. Mount coverslips with the cell side down onto microscope slides in $90 \%$ glycerol in PBS, and seal with clear nail polish.

8. Quantify phagocytosis via phase contrast and fluorescence microscopy by counting at least 200 neutrophils per coverslip (see Note 14).

1. Incubate neutrophils with conidia of $A$. fumigatus at an effector to fungal cell ratio of 10:1 for $120 \mathrm{~min}$ in a final volume of $100 \mu \mathrm{L}$ in 96-well flat-bottomed microtiter plates.

2. After incubation, freeze plates at $-80{ }^{\circ} \mathrm{C}$ and rapidly thaw at $37^{\circ} \mathrm{C}$ to lyse cells and harvest conidia.

3. Prepare serial dilutions (1:10) from each well in PBS $(900 \mu \mathrm{L})$ and plate $100 \mu \mathrm{L}$ onto Sabouraud dextrose agar plates.

4. Incubate plates at $28^{\circ} \mathrm{C}$ for $48 \mathrm{~h}$.

5. Count the number of colony-forming units (CFU) and calculate the percentage of $\mathrm{CFU}$ inhibition (referred to as the fungicidal activity) (see Note 15). 


\section{Notes}

1. It is recommended to add $\beta$-mercaptoethanol to the genomic lysis buffer at a final dilution of $0.5 \%(\mathrm{v} / \mathrm{v})$ to improve lysis performance.

2. Ensure that the elution process occurs for at least $1 \mathrm{~min}$ to increase the DNA yield.

3 . The use of at least $20 \mathrm{ng}$ of DNA in each genotyping reaction is recommended. Use an identical DNA concentration for all samples in order to adequately normalize the fluorescence intensity.

4. The thermal profile presented is a typical example that has been specifically provided by the manufacturer with some minor modifications. Because of the underlying chemistry mechanisms of KASPar, the post-PCR read should always be performed below $40{ }^{\circ} \mathrm{C}$.

5. An optimal cluster visualization is typically obtained using a 7500 Fast qPCR system (Applied Biosystems) and a post-PCR read at $25{ }^{\circ} \mathrm{C}$.

6. Take care to preserve the interface between the Histopaque and the diluted blood solution, thereby avoiding contamination between both phases.

7. The temperature of $20{ }^{\circ} \mathrm{C}$ is crucial to achieve the best cell separation performance.

8. After separation, cells should be kept on ice at all times and handled gently to prevent damage or undesired activation of neutrophils.

9. Complete removal of liquid from the wells by inverting the plate and blotting it against clean paper towels is essential for an optimal performance of the ELISA test.

10. Avoid exposing the plate to light.

11. The length of incubation may vary depending on the concentration of PTX3. For that reason, check the plate every 5 min and stop the reaction earlier, if necessary.

12. If wavelength correction is available, set it to $540 \mathrm{~nm}$ or $570 \mathrm{~nm}$. If wavelength correction is not available, subtract readings at $540 \mathrm{~nm}$ or $570 \mathrm{~nm}$ from the readings at $450 \mathrm{~nm}$ in order to correct for optical imperfections in the plate.

13. For the staining of live conidia of $A$. fumigatus, incubate $2 \times 10^{7}$ conidia in $2 \mathrm{~mL}$ of $\mathrm{Na}_{2} \mathrm{CO}_{3} 50 \mathrm{mM}$ buffer, $\mathrm{pH} 10.2$ with FITC at a final concentration of $0.1 \mathrm{mg} / \mathrm{mL}$ (prepared in the same buffer) at $37^{\circ} \mathrm{C}$ for $4 \mathrm{~h}$. Wash the conidia thoroughly to eliminate residual FITC. 
14. Enumerate the number of ingested conidia, or bound but not ingested. The data is typically presented as the percentage of neutrophils ingesting one or more conidia.

15. Calculate the inhibition of CFU-also known as fungicidal activity - using the following formula: \% fungicidal activity $=(1-X / C) \times 100$ where $X$ is the number of CFU obtained after infection of neutrophils, and $C$ is the number of CFU in the absence of neutrophils. Perform three biological replicates for each condition and at least two technical replicates.

\section{Acknowledgements}

This work was supported by the European Society of Clinical Microbiology and Infectious Diseases (Research Grant 2012 to A.C.) and the Fundação para a Ciência e Tecnologia (FCT) (SFRH/ BPD/96176/2013 to C.C. and IF/00735/2014 to A.C.). Further support was provided by FCT, cofunded by Programa Operacional Regional do Norte (ON.2-O Novo Norte), the Quadro de Referência Estratégico Nacional (QREN) through the Fundo Europeu de Desenvolvimento Regional (FEDER), and the Projeto Estratégico PEst-C/SAU/LA0026/2013.

\section{References}

1. Segal BH (2009) Aspergillosis. N Engl J Med 360(18):1870-1884. doi:10.1056/ NEJMra0808853

2. Kontoyiannis DP, Marr KA, Park BJ, Alexander BD, Anaissie EJ, Walsh TJ et al (2010) Prospective surveillance for invasive fungal infections in hematopoietic stem cell transplant recipients, 2001-2006: overview of the Transplant-Associated Infection Surveillance Network (TRANSNET) Database. Clin Infect Dis 50(8):1091-1100. doi:10.1086/ 651263

3. Pagano L, Caira M, Candoni A, Offidani M, Martino B, Specchia G et al (2010) Invasive aspergillosis in patients with acute myeloid leukemia: a SEIFEM-2008 registry study. Haematologica 95(4):644-650. doi:10.3324/ haematol.2009.012054

4. Vinh DC (2011) Insights into human antifungal immunity from primary immunodeficiencies. Lancet Infect Dis 11(10):780-792. doi:10.1016/S1473-3099(11)70217-1

5. Cunha C, Aversa F, Romani L, Carvalho A (2013) Human genetic susceptibility to invasive aspergillosis. PLoS Pathog 9(8), el 003434. doi:10.1371/journal.ppat.1003434
6. Wojtowicz A, Bochud PY (2014) Host genetics of invasive Aspergillus and Candida infections. Semin Immunopathol. doi:10.1007/ s00281-014-0468-y

7. Koldehoff M, Beelen DW, Elmaagacli AH (2013) Increased susceptibility for aspergillosis and post-transplant immune deficiency in patients with gene variants of TLR4 after stem cell transplantation. Transpl Infect Dis 15(5):533-539. doi:10.1111/tid.12115

8. Bochud PY, Chien JW, Marr KA, Leisenring WM, Upton A, Janer M et al (2008) Toll-like receptor 4 polymorphisms and aspergillosis in stem-cell transplantation. N Engl J Med 359(17):1766-1777. doi:10.1056/NEJMoa0802629

9. Carvalho A, Pasqualotto AC, Pitzurra L, Romani L, Denning DW, Rodrigues F (2008) Polymorphisms in toll-like receptor genes and susceptibility to pulmonary aspergillosis. J Infect Dis 197(4):618-621. doi:10.1086/526500

10. Carvalho A, Cunha C, Carotti A, Aloisi T, Guarrera O, Di Ianni M et al (2009) Polymorphisms in Toll-like receptor genes and susceptibility to infections in allogeneic stem cell transplantation. Exp Hematol 37(9):10221029. doi:10.1016/j.exphem.2009.06.004 
11. Carvalho A, De Luca A, Bozza S, Cunha C, D'Angelo C, Moretti S et al (2012) TLR3 essentially promotes protective class I-restricted memory CD8(+) T-cell responses to Aspergillus fumigatus in hematopoietic transplanted patients. Blood 119(4):967-977. doi:10.1182/ blood-2011-06-362582

12. Potenza L, Vallerini D, Barozzi P, Riva G, Forghieri F, Beauvais A et al (2013) Characterization of specific immune responses to different Aspergillus antigens during the course of invasive Aspergillosis in hematologic patients. PLoS One 8(9), e74326. doi:10.1371/journal.pone.0074326

13. Sorci G, Giovannini G, Riuzzi F, Bonifazi P, Zelante T, Zagarella S et al (2011) The danger signal S100B integrates pathogen- and dangersensing pathways to restrain inflammation. PLoS Pathog 7(3), el001315. doi:10.1371/ journal.ppat.1001315

14. Cunha C, Giovannini G, Pierini A, Bell AS, Sorci G, Riuzzi F et al (2011) Geneticallydetermined hyperfunction of the S100B/RAGE axis is a risk factor for aspergillosis in stem cell transplant recipients. PLoS One 6(11), e27962. doi:10.1371/journal.pone.0027962

15. Kesh S, Mensah NY, Peterlongo P, Jaffe D, Hsu $\mathrm{K}, \mathrm{M}$ VDB et al. TLRl and TLR6 polymorphisms are associated with susceptibility to invasive aspergillosis after allogeneic stem cell transplantation. Ann NY Acad Sci. 2005;1062:95103. doi: 10.1196/annals.1358.012

16. Grube M, Loeffler J, Mezger M, Kruger B, Echtenacher B, Hoffmann P et al (2013) TLR5 stop codon polymorphism is associated with invasive aspergillosis after allogeneic stem cell transplantation. Med Mycol 51(8):818825. doi:10.3109/13693786.2013.809630

17. Chai LY, de Boer MG, van der Velden WJ, Plantinga TS, van Spriel AB, Jacobs C et al (2011) The Y238X stop codon polymorphism in the human beta-glucan receptor dectin-1 and susceptibility to invasive aspergillosis. J Infect Dis 203(5):736-743. doi:10.1093/ infdis/jiq102

18. Cunha C, Di Ianni M, Bozza S, Giovannini G, Zagarella S, Zelante T et al (2010) Dectin-1 Y238X polymorphism associates with susceptibility to invasive aspergillosis in hematopoietic transplantation through impairment of both recipient- and donor-dependent mechanisms of antifungal immunity. Blood 116(24):53945402. doi:10.1182/blood-2010-04-279307

19. Sainz J, Lupianez CB, Segura-Catena J, Vazquez L, Rios R, Oyonarte S et al (2012) Dectin-1 and DC-SIGN polymorphisms associated with invasive pulmonary Aspergillosis infection. PLoS One 7(2), e32273. doi:10.1371/journal. pone. 0032273
20. Ferwerda B, Ferwerda G, Plantinga TS, Willment JA, van Spriel AB, Venselaar H et al (2009) Human dectin-1 deficiency and mucocutaneous fungal infections. $\mathrm{N}$ Engl J Med 361(18):1760-1767. doi:10.1056/ NEJMoa0901053

21. Carvalho A, Cunha C, Di Ianni M, Pitzurra L, Aloisi T, Falzetti F et al (2010) Prognostic significance of genetic variants in the IL-23/ Th17 pathway for the outcome of $\mathrm{T}$ celldepleted allogeneic stem cell transplantation. Bone Marrow Transplant 45(11):1645-1652. doi:10.1038/bmt.2010.28

22. Mezger M, Steffens M, Beyer M, Manger C, Eberle J, Toliat MR et al (2008) Polymorphisms in the chemokine (C-X-C motif) ligand 10 are associated with invasive aspergillosis after allogeneic stem-cell transplantation and influence CXCL10 expression in monocyte-derived dendritic cells. Blood 111(2):534-536. doi:10.1182/blood-2007-05-090928

23. Sainz J, Hassan L, Perez E, Romero A, Moratalla A, Lopez-Fernandez E et al (2007) Interleukin-10 promoter polymorphism as risk factor to develop invasive pulmonary aspergillosis. Immunol Lett 109(1):76-82. doi:10.1016/j.imlet.2007.01.005

24. Sainz J, Perez E, Gomez-Lopera S, Jurado M (2008) ILl gene cluster polymorphisms and its haplotypes may predict the risk to develop invasive pulmonary aspergillosis and modulate C-reactive protein level. J Clin Immunol 28(5):473-485. doi:10.1007/s10875-008-9197-0

25. Sainz J, Perez E, Hassan L, Moratalla A, Romero A, Collado MD et al (2007) Variable number of tandem repeats of TNF receptor type 2 promoter as genetic biomarker of susceptibility to develop invasive pulmonary aspergillosis. Hum Immunol 68(1):41-50. doi:10.1016/j.humimm.2006.10.011

26. Sainz J, Salas-Alvarado I, Lopez-Fernandez E, Olmedo C, Comino A, Garcia F et al (2010) TNFRl mRNA expression level and TNFRl gene polymorphisms are predictive markers for susceptibility to develop invasive pulmonary aspergillosis. Int J Immunopathol Pharmacol 23(2):423-436

27. Wojtowicz A, Gresnigt MS, Lecompte T, Bibert S, Manuel O, Joosten LA et al (2014) ILIB and DEFBl polymorphisms increase susceptibility to invasive mould infection after solid-organ transplantation. J Infect Dis. doi:10.1093/infdis/jiu636

28. Kumar V, Cheng SC, Johnson MD, Smeekens SP, Wojtowicz A, Giamarellos-Bourboulis E et al (2014) Immunochip SNP array identifies novel genetic variants conferring susceptibility to candidaemia. Nat Commun 5:4675. doi:10.1038/ ncomms 5675 
29. Smeekens SP, Ng A, Kumar V, Johnson MD, Plantinga TS, van Diemen C et al (2013) Functional genomics identifies type I interferon pathway as central for host defense against Candida albicans. Nat Commun 4:1342. doi: $10.1038 /$ ncomms 2343

30. Fairfax BP, Knight JC (2014) Genetics of gene expression in immunity to infection. Curr Opin Immunol 30C:63-71. doi:10.1016/j. coi.2014.07.001

31. Durrant C, Tayem H, Yalcin B, Cleak J, Goodstadt L, de Villena FP et al (2011) Collaborative cross mice and their power to map host susceptibility to Aspergillus fumigatus infection. Genome Res 21(8):1239-1248. doi:10.1101/gr.118786.110

32. Zaas AK, Liao G, Chien JW, Weinberg C, Shore D, Giles SS et al (2008) Plasminogen alleles influence susceptibility to invasive aspergillosis. PLoS Genet 4(6), el000101. doi:10.1371/journal.pgen.1000101

33. Lambourne J, Agranoff D, Herbrecht R, Troke PF, Buchbinder A, Willis F et al (2009) Association of mannose-binding lectin deficiency with acute invasive aspergillosis in immunocompromised patients. Clin Infect Dis 49(10):1486-1491. doi:10.1086/644619
34. Cunha C, Aversa F, Lacerda JF, Busca A, Kurzai O, Grube M et al (2014) Genetic PTX3 deficiency and aspergillosis in stem-cell transplantation. N Engl J Med 370(5):421-432. doi:10.1056/NEJMoal211161

35. Wojtowicz A, Lecompte TD, Bibert S, Manuel O, Rueger S, Berger C et al (2015) PTX3 polymorphisms and invasive mould infections after solid organ transplant. Clin Infect Dis 61(4):619-622. doi:10.1093/cid/civ386

36. Cunha C, Monteiro AA, Oliveira-Coelho A, Kuhne J, Rodrigues F, Sasaki SD et al (2015) PTX3-based genetic testing for risk of aspergillosis after lung transplant. Clin Infect Dis 61(12):1893-1894. doi:10.1093/cid/ civ679

37. Mauri T, Coppadoro A, Bombino M, Bellani G, Zambelli V, Fornari C et al (2014) Alveolar pentraxin 3 as an early marker of microbiologically confirmed pneumonia: a threshold-finding prospective observational study. Crit Care 18(5):562. doi:10.1186/ sl3054-014-0562-5

38. Carvalho A, Cunha C, Bistoni F, Romani L (2012) Immunotherapy of aspergillosis. Clin MicrobiolInfect18(2):120-125.doi:10.1111/j.1469$0691.2011 .03681 . x$ 